\title{
Meloxicam Taste-Masked Oral Disintegrating Tablet with Dissolution Enhanced by Ion Exchange Resins and Cyclodextrin
}

\author{
Wipada Samprasit, ${ }^{1}$ Prasert Akkaramongkolporn, ${ }^{1}$ Tanasait Ngawhirunpat, ${ }^{1}$ Theerasak Rojanarata, ${ }^{1}$ and \\ Praneet Opanasopit ${ }^{1,2}$
}

Received 31 January 2013; accepted 25 June 2013; published online 9 July 2013

Abstract. The purpose of this study was to develop taste-masked oral disintegrating tablets (ODTs) using the combination of ion exchange resin and cyclodextrin, to mask the bitter taste and enhance drug dissolution. Meloxicam (MX) was selected as a model drug with poor water solubility and a bitter taste. Formulations containing various forms of MX (free drug, MX-loaded resin or resinate, complexes of MX and 2-hydroxypropyl- $\beta$-cyclodextrin $(\mathrm{HP} \beta \mathrm{CD})$ or $\mathrm{MX} / \mathrm{HP} \beta \mathrm{CD}$ complexes, and a mixture of resinate and $\mathrm{MX} / \mathrm{HP} \beta \mathrm{CD}$ complexes) were made and tablets were prepared by direct compression. The ODTs were evaluated for weight variation, thickness, diameter, hardness, friability, disintegration time, wetting time, MX content, MX release, degree of bitter taste, and stability. The results showed that thickness, diameter, weight, and friability did not differ significantly for all of these formulations. The tablet hardness was approximately $3 \mathrm{~kg} / \mathrm{in} .{ }^{2}$, and the friability was less than $1 \%$. Tablets formulated with resinate and the mixture of resinate and MX/HP $\beta C D$ complexes disintegrated rapidly within $60 \mathrm{~s}$, which is the acceptable limit for ODTs. These results corresponded to the in vivo disintegration and wetting times. However, only tablets containing the mixture of resinate and MX/HP $\beta \mathrm{CD}$ complexes provided complete MX dissolution and successfully masked the bitter taste of MX. In addition, this tablet was stable at least 6 months. The results from this study suggest that the appropriate combination of ion exchange resin and cyclodextrin could be used in ODTs to mask the bitter taste of drug and enhance the dissolution of drugs that are weakly soluble in water.

KEY WORDS: cyclodextrin; ion exchange resins; oral disintegrating tablet; taste masking.

\section{INTRODUCTION}

Dysphagia or difficulty in swallowing tablets is a common condition in all age groups. Thirty-five percent of the population and $40 \%$ of the elderly have this problem (1). Dysphagia is also an issue for pediatric patients and patients who lack ready access to water for swallowing dosage forms. To overcome this problem, there are new drug delivery dosage forms known as oral disintegrating tablets (ODTs). These solids dosage forms can be dissolved or suspended with saliva in the mouth for easy swallowing. Generally, they disintegrate within 60 s or less (2), and the drug is absorbed through the local oral mucosal tissues or the gastrointestinal (GI) tract. Their major advantage is that ODTs can be taken without water, and they are suitable for geriatric and pediatric patients. Additional benefits in patient compliance, onset of action, and bioavailability that make ODTs the tablet of choice in the current market.

\footnotetext{
${ }^{1}$ Pharmaceutical Development of Green Innovations Group (PDGIG), Faculty of Pharmacy, Silpakorn University, Nakhon Pathom 73000, Thailand.

${ }^{2}$ To whom correspondence should be addressed. (e-mail: praneet@su.ac.th)
}

Disintegration time and taste masking are primary considerations in the formulation of ODTs. To provide rapid disintegration, ODTs are commonly formulated with watersoluble excipients or disintegrants. Taste masking of ODTs is necessary because the taste of most drugs produces an unpleasant sensation in the oral cavity after the tablet disintegrates. Current taste-masking methods, including sweeteners and flavors (3), are not sufficient for use in ODTs. Thus, new taste-masking techniques have been developed recently, i.e., complexation, microencapsulation, and ion exchange resins $(2,4)$. Ion exchange resins have received considerable attention for pharmaceutical applications. An ion exchange resin consists of two components: a cross-linked polymer matrix and a functional component with bound counter ions (5). Exchange of an ionized drug molecules with counter ions binds the drug to the resin, forming a "resinate". The drug resinate does not come in contact with the taste buds of a patient, and so its bitter taste is masked during administration. In the GI tract, exchange of ions in the gastric fluid releases the drug from the resinate. However, the controlled release of drugs from physical mixtures of drugs and ion exchange resins, or resinates, can delay the onset of action $(4,6)$. To circumvent this effect, taste masking by complexation with cyclodextrins has been developed (7). A cyclodextrin molecule has a 
lipophilic cavity that forms an inclusion complex by accepting an entire molecule or the non-polar part of a molecule into the cavity (8). A cyclodextrin inclusion complex reduces the unpleasant odor and taste by encapsulating the drug molecules at the molecular level (9). An inclusion complex is usually more hydrophilic and rapidly wetting than the free drug, and it enhances the dissolution and bioavailability of the drug. Therefore, the combination of ion exchange resins and cyclodextrin has promise for the development of ODTs for weakly water-soluble drugs with bitter taste.

Meloxicam (MX) is a class of non-steroidal anti-inflammatory drugs with poor aqueous solubility and bitter taste. The drug is produced commercially in various dosage forms including suspensions and tablets (10). These dosage forms have received poor acceptance from patients because of their taste is bitter and they are difficult to swallow. In addition, incomplete drug absorption after oral administration has occurred due to its low solubility. Thus, this study was focused on the development of ODTs using combinations of ion exchange resins (Dowex ${ }^{\circledR}$ $1 \times 2-200)$ and 2-hydroxypropyl- $\beta$-cyclodextrin (HP $\beta C D)$ to mask the bitter taste and enhance dissolution of MX. Tablets containing various drug forms (free drug, resinate, MX/HP $\beta C D$ complexes, and the mixture of resinate and MX/HP $\beta \mathrm{CD}$ complexes) were prepared and evaluated for properties that included disintegration time, taste, and dissolution profiles.

\section{MATERIALS AND METHODS}

\section{Materials}

Meloxicam, 2-hydroxypropyl- $\beta$-cyclodextrin (HP $\beta C D)$ with molar substitution 0.6, poly(styrene-co-divinylbenzene) sodium sulfonate (Amberlite $\AA$ IRP-69), and poly(styrene-codivinylbenzene) with dimethylamine functional group in the chloride form (Dowex® 1x2-200) were purchased from Sigma Chemical Co., USA. Microcrystalline cellulose (Comprecel® M102 D+; Mingtai chemical, Taiwan.), spray dried lactose (Super-Tab® 11SD; DMV-fonterra excipients $\mathrm{GmbH}$ \& Co., Germany), Crospovidone (Kollidon ${ }^{\circledR C L}$; BASF, Germany), mannitol (Merck, Germany), 12× grades of icing sugar, and magnesium stearate were purchased and used as received. The reagents were analytical grade. Only deionized water was used in this work.

Methods

Preparation of $M X$ Resinate

First, saturated solutions of MX were prepared as follows. An excess amount of MX $(800 \mathrm{mg}$ ) was added to $500 \mathrm{ml}$ of phosphate buffer solution at $\mathrm{pH} 8$. The mixture was vigorously shaken on a magnetic stirrer at $25^{\circ} \mathrm{C}$ for $24 \mathrm{~h}$. Then, the sample was filtered through a $0.45 \mu \mathrm{m}$ membrane filter to remove any undissolved solids. The dissolved MX was assayed at a wavelength of $362 \mathrm{~nm}$ by UV-Visible spectrophotometry $\left(\right.$ NanoVue $^{\mathrm{TM}}$, GE Healthcare, UK). A MX resinate was prepared by a batch method (11). The saturated MX solution were equilibrated with Dowex® 1x2-200 resin at 0.5:1, 1:1, 2:1 and 4:1 weight ratios of $\mathrm{MX}$ to resin while stirring magnetically at $25^{\circ} \mathrm{C}$ for $48 \mathrm{~h}$. To determine the equilibrium MX loading, a small amount of supernatant was collected at predetermined times to assay the changes of MX concentration. After equilibration, the resinate was collected by filtration, washed several times with copious amounts of deionized water, and dried at $50^{\circ} \mathrm{C}$ overnight in a hot air oven. The percentage of MX loading on the resin was determined by an elution method (12). The resinate $(3 \mathrm{mg}$ ) was accurately weighed and placed in a volumetric flask that contained $50 \mathrm{ml}$ of $2 \mathrm{~N}$ potassium chloride $(\mathrm{KCl})$ solution. The mixture was stirred magnetically for $24 \mathrm{~h}$ and the eluted MX was assayed by spectrophotometry. The MX loading ( $\% w / w)$ of the resinate was calculated with the following equation:

$\% \mathrm{MX}$ loading $=\left(\mathrm{MX}_{\mathrm{EL}} / W\right) \times 100$

where $\mathrm{MX}_{\mathrm{EL}}$ and $\mathrm{W}$ are the amounts of eluted $\mathrm{MX}$ and resinate, respectively.

\section{Characterization of $M X$ Resinate}

1. Scanning electron microscopy (SEM)

The surface morphology of MX, Dowex ${ }^{\circledR}$ resin and MX resinate at 2:1 weight, ratio of $\mathrm{MX}$ to resin were examined. The samples were attached to aluminum stubs with double side adhesive carbon tape then gold coated with a sputter coater and examined using a scanning electron microscope (Camscan Mx2000, England). The particle size of Dowex ${ }^{\circledR}$ resin and MX resinate were determined by using image analysis software (JMicroVision V.1.2.7, Switzerland).

\section{X-ray diffractometry (XRD)}

The powder X-ray patterns of MX, Dowex® resin and $\mathrm{MX}$ resinate at 2:1 weight ratio of $\mathrm{MX}$ to resin were recorded using a X-ray powder diffractometer (model miniflex II, Rigaku Co., Japan). Sample was irradiated with monochromatized $\mathrm{CuKa}$ radiation after passing through Nickel filters and then was analyzed between $5^{\circ}$ and $45^{\circ}(2 \theta)$. The voltage and current applied were $30 \mathrm{kV}$ and $15 \mathrm{~mA}$, respectively.

\section{Differential scanning calorimetry (DSC)}

The thermal behavior of MX, Dowex ${ }^{\circledR}$ resin and MX resinate at 2:1 weight ratio of $\mathrm{MX}$ to resin were determined by using DSC (Perkin Elmer, Germany). Sample (2-4 mg) was placed in an aluminum pan and crimped with its cover to provide hermetically sealed samples. The heating rate was $10^{\circ} \mathrm{C} / \mathrm{min}$. All measurements were obtained over $25-300^{\circ} \mathrm{C}$ under nitrogen.

\section{MX/Cyclodextrin Complexation}

The MX/HP $\beta C D$ complexation was studied by using phase solubility methods at pH 1.2 and 6.8 as previously described (13). An excess amount of MX (50 mg) was weighed and placed in a microcentrifuge tube containing $1 \mathrm{ml}$ of $\mathrm{HP} \beta C D$ (in the $0-15 \mathrm{mM}$ range). The sample was agitated on a horizontal movement shaker $(30 \mathrm{rpm})$ at $25^{\circ} \mathrm{C}$ until it reached equilibrium $(24 \mathrm{~h})$. After equilibrium, the MX concentration did not change. Samples were collected and centrifuged, and the MX was quantified by UVVisible spectroscopy at wavelengths of 345 and $362 \mathrm{~nm}$ for $\mathrm{pH} 1.2$ and 6.8 , respectively. The stability constant of the complex $\left(K_{\mathrm{c}}\right)$ was calculated according to the following equation: 
$K_{\mathrm{c}}=$ slope $/\left[S_{0}(1-\right.$ slope $\left.)\right]$

where slope is the slope of the phase solubility diagram, which plots molar concentrations of MX solubility against $\mathrm{HP} \beta \mathrm{CD}$ molar concentration, and $S_{0}$ is the MX solubility without $\mathrm{HP} \beta \mathrm{CD}$.

The stoichiometry of the inclusion complex was determined by the continuous variation method, which was carried out according to Job (14). Equimolar stock solutions (0.005 and $0.05 \mathrm{mM}$ for $\mathrm{pH} 1.2$ and 6.8, respectively) of $\mathrm{MX}$ and $\mathrm{HP} \beta \mathrm{CD}$ were prepared, and then proportionally mixed to obtain solutions containing various molar ratios of MX and $\mathrm{HP} \beta \mathrm{CD}$. The total concentration of these solutions was kept constant at 0.005 and $0.050 \mathrm{mM}$ for $\mathrm{pH} 1.2$ and 6.8, respectively. After stirring at $25^{\circ} \mathrm{C}$ for $24 \mathrm{~h}$, the absorbance of MX was measured at the wavelengths of 345 and $362 \mathrm{~nm}$ for $\mathrm{pH}$ 1.2 and 6.8 , respectively, and the difference in absorbance between MX with and without $\operatorname{HP} \beta C D(\Delta A)$ was plotted against the molar fraction of $\mathrm{MX}(R)$, which was calculated from the following equation:

$R=[\mathrm{MX}] /([\mathrm{MX}]+[\mathrm{HP} \beta \mathrm{CD}])$

\section{The Mixture Ratio of Resinate and MX/HPßCD Complexes}

The resinate and $\mathrm{MX} / \mathrm{HP} \beta \mathrm{CD}$ complexes were mixed at $1: 0.5,1: 1$, and 1:2 weight ratios of resinate to $\mathrm{MX} / \mathrm{HP} \beta \mathrm{CD}$ complexes. Each ratio was blended in a plastic bottle for $10 \mathrm{~min}$.

\section{In Vitro Dissolution Test of Powders}

The resinate, the MX/HP $\beta C D$ complexes and the mixture of resinate and $\mathrm{MX} / \mathrm{HP} \beta \mathrm{CD}$ complexes, as powders containing an equivalent dose $(7.5 \mathrm{mg})$ of $\mathrm{MX}$, were evaluated with in vitro dissolution profiles. In vitro dissolution studies were performed in $0.1 \mathrm{~N} \mathrm{HCl}(750 \mathrm{ml})$ for $2 \mathrm{~h}$ using a USP dissolution testing apparatus II (type PTW, Pharmatest, Germany) at $37 \pm 0.5^{\circ} \mathrm{C}$ with a rotation speed of $50 \mathrm{rpm}$. After $2 \mathrm{~h}$, the $\mathrm{pH}$ was changed to $\mathrm{pH} 6.8$ by the addition of $250 \mathrm{ml}$ of a $0.20 \mathrm{M}$ solution of trisodium phosphate, which was equilibrated to $37^{\circ} \mathrm{C}$. The MX release was measured at predetermined times; samples of medium $(5 \mathrm{ml})$ were collected and replaced with fresh medium, and analyzed by UV-Visible spectrophotometry at wavelengths of 345 and $362 \mathrm{~nm}$ for $\mathrm{pH} 1.2$ and 6.8, respectively. The mixture of resinate and MX/HP $\beta C D$ complexes with the highest dissolution profile was used to formulate the ODTs for the next experiment.

\section{Preparation of Meloxicam ODTs}

Several ODTs containing equivalent doses $(7.5 \mathrm{mg})$ of MX in the free drug, resinate, MX/HP $\beta C D$ complexes and the mixture with a 1:2 weight ratio of resinate and MX/HP $\beta C D$ complexes were developed. The formulae of meloxicam ODTs are summarized in Table I. Fixed amounts of mannitol and icing sugar were used as sweetening agents. Icing sugar is a mixture of sucrose (not less than 95\%) and corn starch that has been ground to a fine powder. It is used in pharmaceutical formulations when a rapidly dissolving form of sugar is required for sweetening agent. Super-Tab® ${ }^{\circledR} 11$ SD was used as a direct compression filler due to its water solubility and safety. However, using Super-Tab® 11SD alone as a filler causes unacceptable hardness. Therefore, Comprecel ${ }^{\circledR}$ M102 D+ was selected as additional filler to improve hardness and prevent capping of tablets, and it was fixed at $20 \%$ of tablet by mass. Two types of super-disintegrants, Kollidon ${ }^{\circledR C L}$ and ion exchange resins (Dowex ${ }^{\circledR}$ 1x2-200 and Amberlite ${ }^{\circledR}$ IRP-69), were used to achieve rapid tablet disintegration $(5,15)$. All materials, except magnesium stearate that was used as a lubricant, were blended in a plastic bottle for $10 \mathrm{~min}$. Then, the lubricant was added and materials were mixed for an additional $3 \mathrm{~min}$. A portion of the mixture was accurately weighed $(200 \mathrm{mg})$, transferred to a hand hydraulic press machine (Specac P/N 15011,25011, UK), and compressed at a constant force $(29.4 \mathrm{kN})$ using stainless steel flat-face punches with a diameter of $9.53 \mathrm{~mm}$.

\section{Evaluation of Meloxicam ODTs}

\section{MX content}

The amount of $\mathrm{MX}$ in a tablet was determined by crushing the tablet in a mortar. Then, the crushed powder was weighed and transferred into a 250-ml volumetric flask, and $2 \mathrm{~N} \mathrm{KCl}, \mathrm{pH} 8$, solution was added to adjust the volume. The mixture was stirred magnetically for $24 \mathrm{~h}$. The supernatant was filtered and assayed by UV-Visible spectrophotometry at the wavelength of $362 \mathrm{~nm}$. The MX content was calculated and expressed as \% labeled amount.

Weight, thickness, diameter, hardness, and friability The prepared tablets were evaluated for uniformity of weight, thickness, diameter hardness, and friability. Tablets were individually weighed on an analytical balance, and the average weight and standard deviation were calculated. The thickness and diameter were measured with a micrometer (Sylvac S229, Switzerland). The hardness was measured with a Monsanto hardness tester (Sheetal Scientific Industries, Mumbai, India). The friability was determined with a Roche friabilator (Yeoheng Co., Thailand). Twenty tablets were weighed $\left(W_{1}\right)$ and placed into the friabilator, which rotated at $25 \mathrm{rpm}$ for $4 \mathrm{~min}$. The tablets were then reweighed after removal of fines $\left(W_{2}\right)$, and the friability was calculated according to the following equation:

$\%$ friability $=\left(W_{1}-W_{2}\right) / W_{1} \times 100$

\section{In vitro disintegration time}

In vitro disintegration of tablets in artificial saliva was determined using a USP disintegration testing apparatus (Sotax DT3, Switzerland) (10). The artificial saliva consisted of $0.238 \mathrm{~g} \mathrm{Na}_{2} \mathrm{HPO}_{4}, 0.019 \mathrm{~g} \mathrm{KH}_{2} \mathrm{PO}_{4}$, and $0.8 \mathrm{~g} \mathrm{NaCl}$ per $800 \mathrm{ml}$ of deionized water, which was adjusted to $\mathrm{pH} 6.8$ with phosphoric acid (16). The medium was maintained at $37 \pm 0.5^{\circ} \mathrm{C}$ throughout the test. Six tablets were placed into a basket-rack assembly and covered with a transparent plastic disc. The disintegration time was the time required for the tablets to disintegrate completely and pass through the screen of the basket-rack assembly. 
Table I. Composition of Meloxicam ODTs

\begin{tabular}{|c|c|c|c|c|c|c|}
\hline Ingredient (mg) & $\mathrm{F} 1$ & $\mathrm{~F} 2$ & F3 & F4 & F5 & F6 \\
\hline Meloxicam (MX) & 7.5 & - & - & - & - & - \\
\hline MX resinate & - & 15 & - & 5 & - & 5 \\
\hline MX/HP $\beta C D$ complexes & - & - & $7.5 / 29.45$ & $5 / 19.65$ & $7.5 / 29.45$ & $5 / 19.65$ \\
\hline Mannitol (10\%) & 20 & 20 & 20 & 20 & 20 & 20 \\
\hline Icing sugar $(10 \%)$ & 20 & 20 & 20 & 20 & 20 & 20 \\
\hline Comprecel® M102 D+ (20\%) & 40 & 40 & 40 & 40 & 40 & 40 \\
\hline Kollidon®CL (5\%) & 10 & 10 & 10 & 10 & 10 & \\
\hline Amberlite® IRP-69 (20\%) & - & - & - & - & 40 & \\
\hline Magnesium stearate $(0.5 \%)$ & 1 & 1 & 1 & 1 & 1 & \\
\hline Super-Tab® $11 S D$ q.s. to & 200 & 200 & 200 & 200 & 200 & \\
\hline
\end{tabular}

The wetting time was measured by a procedure that simulates the physiological conditions under the surface of a moist tongue $(11,17)$. The tests were carried out with methods that were slightly modified from previous work (17). A piece of paper tissue was folded twice and placed in a $10 \mathrm{~cm}$ diameter plastic dish containing $10 \mathrm{ml}$ of artificial saliva. A tablet was placed at the center of the folded paper, and the time required for the water to diffuse from the wetted absorbent paper throughout the entire tablet was recorded as the wetting time. The images of the tablet were recorded at several times until the tablets were completely wetted.

5. In vivo disintegration time and taste evaluation In vivo disintegration time and taste evaluation was performed with six healthy human volunteers. This study was approved by an Investigational Review Board (Human Studies Ethics Committee, Faculty of Pharmacy, Silpakorn University, approyal no. 242553). Each volunteer randomly took one tablet and kept on their tongue, the time required for complete disintegration of tablet was recorded as in vivo disintegration time and the bitterness after a tablet completely disintegrated was determined immediately. Afterward, the volunteer rinsed their oral cavity with water without swallowing the disintegrated material and then took another tablet formulation. The taste was evaluated and assigned a numerical value, i.e., $0=$ tasteless, $1=$ slightly bitter, 2 = moderately bitter and $3=$ strongly bitter, respectively.

\section{In vitro dissolution study}

In vitro dissolution studies of ODTs were performed using the same method described above for the in vitro dissolution test of powders.

\section{Stability}

The optimized formulation was stored in a chamber controlled at $40^{\circ} \mathrm{C}$ and $75 \%$ in humidity for 6 months, then the tablet appearance, MX content and in vitro dissolution of tablets were determined after $0,1,3$ and 6 months.
Results were presented as the mean \pm standard deviation of at least triplicate experiments. The statistical significances of the differences in the MX loading of the resinate were examined using one-way analyses of variance. The difference in taste values was analyzed by using the Wilcoxon signed rank test. The significance level was set to $p<0.05$.

\section{RESULTS AND DISCUSSION}

\section{Preparation of MX Resinate}

$\mathrm{MX}$ is a class of non-steroidal anti-inflammatory drugs with weak aqueous solubility. It has two dissociation constants $\left(\mathrm{p} K_{\mathrm{a}}\right), 1.09$ and 4.18. The isoelectric point $(\mathrm{p} I)$ of $\mathrm{MX}$, which was computed from $\left(\mathrm{p} K_{\mathrm{a} 1}+\mathrm{p} K_{\mathrm{a} 2}\right) / 2(18)$, was 2.63. $\mathrm{MX}$ is cationic at $\mathrm{pH}<\mathrm{p} I$, zwitterionic at $\mathrm{pH}=\mathrm{p} I$, and anionic at $\mathrm{pH}>\mathrm{p} I$. Therefore, the condition of $\mathrm{pH}>2.63$ can increase the solubility and ionization of MX into anionic forms that can be exchanged with counter ions to form MX resinates. MX solubility increased when $\mathrm{pH}$ was raised from $\mathrm{pH} 3$ to 8 (13). The maximum solubility was observed at $\mathrm{pH} 8$, which was used to prepare MX resinate to reduce the volume and increase the MX concentration of the loaded solution. The resinate was successfully prepared by a batch process. After the resin was placed in the loaded solution, ions from the resin and MX solution diffused (19), and the dissolved MX in its ionized form $\left(\mathrm{MX}^{-}\right)$exchanged with the counter ion $\left(\mathrm{Cl}^{-}\right)$of resin and bound to the resin forming $\left(\mathrm{RN}\left(\mathrm{CH}_{3}\right)_{3} \mathrm{Cl}\right)$ via ion exchange reactions (Eq.5), forming the resinate complex $\left(\mathrm{RN}\left(\mathrm{CH}_{3}\right)_{3} \mathrm{MX}\right)$

$\mathrm{RN}\left(\mathrm{CH}_{3}\right)_{3} \mathrm{Cl}+\mathrm{MX}^{-} \Leftrightarrow \mathrm{RN}\left(\mathrm{CH}_{3}\right)_{3} \mathrm{MX}+\mathrm{Cl}^{-}$

Figure 1 shows the percentage of MX loading onto the resin at various weight ratios of $\mathrm{MX}$ to resin. The percentage of MX loading was affected by the weight ratio of MX to resin and increased as the MX amount increased $(0.5: 1,1: 1,2: 1)$ and then leveled off $(4: 1)$. This was due to the resin was saturated with MX and reached the maximum exchange capacity of the ion exchange resin $(20,21)$. Thus, the weight ratio of MX to resin at 2:1 was selected for the development of taste-masked ODTs. This ratio was 


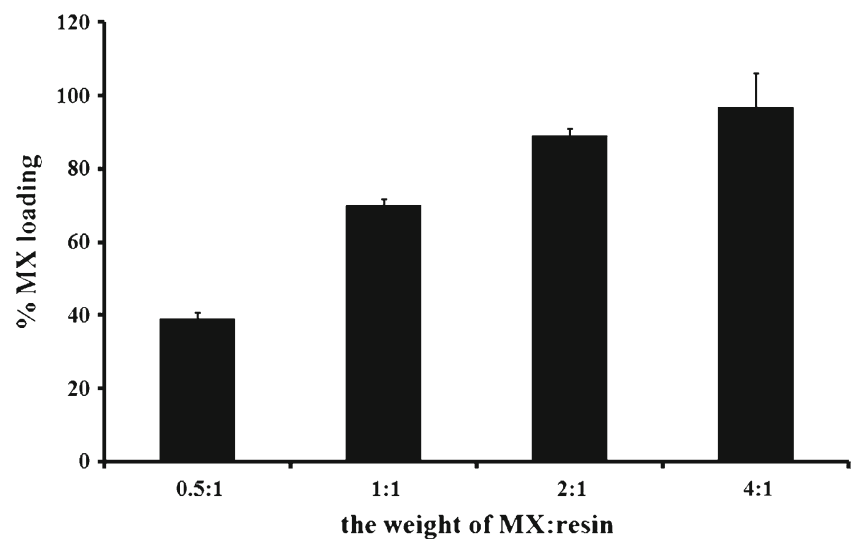

Fig. 1. The percentage of MX loading in resinate at various weight ratios of MX to resin

suitable for MX loading to increase the MX concentration and improve the resultant resinate (22). Under these conditions, the MX content was $49.69 \pm 0.35 \% w / w$ of MX to resinate, according to an elution method.

\section{Characterization of MX Resinate}

Scanning electron microscopes of MX (Fig. 2a), Dowex ${ }^{\circledR}$ resin (Fig. 2b) and MX resinate at 2:1 weight ratio of MX to resin (Fig. 2c) showed that MX had rod-like and plate-like particles, the resins had spherical shape before and after MX loading. The particle sizes of resin were very small $(142.11 \pm$ $11.01 \mu \mathrm{m}$ and $153 \pm 7.98 \mu \mathrm{m}$ before and after MX loading, respectively) which could be used for ODTs formulation. Figure 3 demonstrate the XRD patterns of MX, resin, and MX resinate. MX was crystalline and exhibited a number of sharp peaks, indicating crystalline nature of $\mathrm{MX}$, while the Dowex ${ }^{\circledR}$ resin showed a hollow pattern that indicated an amorphous state of resin. The molecular state of MX resinate shows a hollow pattern and the absence of MX peaks. Thermal behavior of MX, resin and MX resinate were studied by DSC analysis and their thermogram are shown in Fig. 4. The DSC curve of MX shows a sharp endothermic peak at $264^{\circ} \mathrm{C}$ and a gradual exotherm at $268^{\circ} \mathrm{C}$, indicating melting point of $\mathrm{MX}$ and its decomposition, respectively. The DSC curve of resin shows endotherm at $202.9^{\circ} \mathrm{C}$ to indicate the melting point of resin. While thermal behavior of MX resinate shows endotherm at $194.2^{\circ} \mathrm{C}$ without melting point of MX indicating formation of MX resinate. The results from SEM, XRD, and DSC indicated that the molecular state of the entrapped MX in the resinate changed from the crystalline to the amorphous state. From this, it appears that the drug is dispersed monomolecularly in the resinates.

\section{MX/Cyclodextrin Complexation}

MX is hydrophobic, the molecule contains a heterocyclic ring that can form an inclusion complex with cyclodextrin that enhances its solubility. The phase solubility diagram at $\mathrm{pH} 1.2$ (Fig. 5a) and 6.8 (Fig. 5b) shows that the MX solubility increased linearly with $\mathrm{HP} \beta \mathrm{CD}$ concentration, and the stability constant $\left(K_{\mathrm{c}}\right)$, calculated from the slope, was $147.48 \pm 3.22 \mathrm{M}^{-1}$ and $89.10 \pm 2.18 \mathrm{M}^{-1}$ at $\mathrm{pH} 1.2$ and 6.8 , respectively. The complexation stability constant decreased when the $\mathrm{pH}$ increased, affecting the ionization of MX that might interact weakly with cyclodextrin compared to the non-ionized form (23). However, the $\mathrm{MX} / \mathrm{HP} \beta \mathrm{CD}$ complexes at $\mathrm{pH} 1.2$ and 6.8 were sufficient to enhance solubility. This result was consistent with the previous study where cyclodextrin complexation enhanced solubility at acidic and basic pH (13).

The stoichiometry of the MX/HP $\beta$ CD complex was determined from the phase solubility diagrams and the continuous variation method. The phase solubility diagram showed a linear relationship between MX solubility and the $\mathrm{HP} \beta C D$ concentration at both $\mathrm{pH}$ values (Fig. 5a and b). This identified the inclusion complex as type $\mathrm{A}_{\mathrm{L}}$. The slopes of the straight lines were less than 1 , assuming that a 1:1 stoichiometric inclusion complex between MX and HPBCD was formed (24). These results were supported by a continuous variation study where the maximum value of $R$ for the difference in MX absorbance indicated the inclusion complex stoichiometry (25). In the presence of cyclodextrin, the chromophore of MX was transferred from an aqueous medium to non-polar central cavity of cyclodextrin. With this regard, the molecular interaction between the MX molecule and cyclodextrin accompanying with the exclusion of solvate water molecules induced structural modification and hence free movement of electrons onto different energy levels, finally causing the difference in absorbance between MX with and without $\mathrm{HP} \beta \mathrm{CD}(\Delta \mathrm{A})$ plotted against the molar fraction of $\mathrm{MX}(R)$. If the complexation between $\mathrm{MX}$ and cyclodextrin does not occur, a linear relationship between the difference in absorbance $(\Delta A)$ and the molar fraction of $\mathrm{MX}(R)$ will take place. The complexation occurred when increasing the
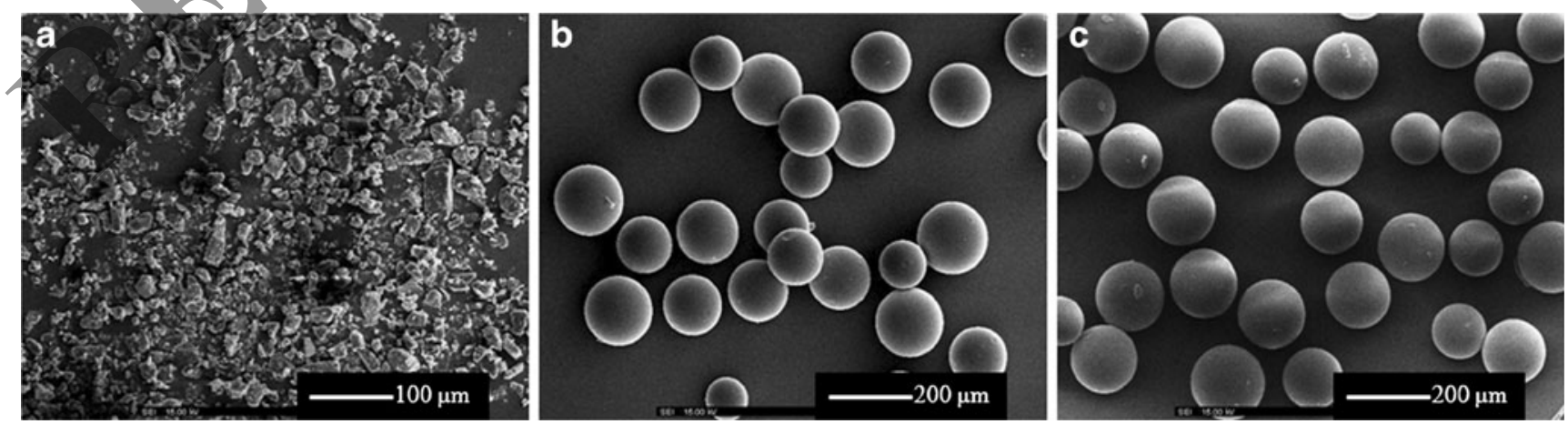

Fig. 2. The scanning electron microscopy (SEM) images of (a) MX, (b) Dowex® resin, and (c) MX resinate 


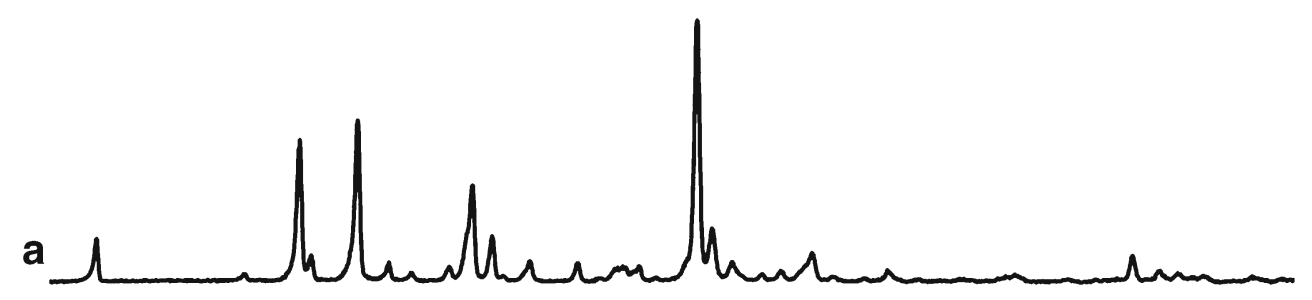

\section{b}

C

molar fraction of $\mathrm{MX}(R)$, the difference in absorbance $(\Delta A)$ reached the highest values with a decrease by further increment of the molar fraction of $\mathrm{MX}(R)$. The maximum difference in absorbance presented the highest molecular interaction between MX molecule and cyclodextrin. The results are shown in Fig. 5c. The profiles were highly symmetrical shape around the maximum difference in absorbance for $\mathrm{HP} \beta \mathrm{CD}$ and $\mathrm{MX}$, which was observed at $R=0.5$, revealing the formation of an inclusion complex with 1:1 stoichiometry. Therefore, the physical mixtures of $\mathrm{MX}$ and $\mathrm{HP} \beta \mathrm{CD}$, or $\mathrm{MX} / \mathrm{HP} \beta \mathrm{CD}$ complexes in the ratio of $1: 1$, was selected for development of taste-masked ODTs. MX and $\mathrm{HP} \beta C D$ would form in situ $\mathrm{MX} / \mathrm{HP} \beta C D$ complexes for the improvement of $\mathrm{MX}$ release at $\mathrm{pH} 1.2$ and 6.8 (26). However, MX and $\mathrm{HP} \beta \mathrm{CD}$ had the absence of strong bonding such as covalent bonding. They were complexed by hydrophobic interaction between heterocyclic ring of MX and central cavity of $H P \beta C D$.

\section{In Vitro Dissolution Test of Powders}

The in itro dissolution profiles of the resinate, MX/ $H P \beta C D$ complexes and the powdered mixtures of resinate and $M X / H P \beta C D$ complexes containing an equivalent dose (7.5 mg) of MX were evaluated. In Fig. 6, MX in the resinate form was released by an ion exchange process between the anion in the release medium and the loaded MX. Then, the MX diffused through the cross-linked structure of the resin. In Fig. 6, there was incomplete MX release due to the equilibration of the ion exchange release process. Thus, the mixtures of resinate and $\mathrm{MX} / \mathrm{HP} \beta \mathrm{CD}$ complexes at various ratios were developed to achieve complete MX release compared to MX/ $\mathrm{HP} \beta \mathrm{CD}$ complexes. The MX release at $6 \mathrm{~h}$ for the 1:0.5, 1:1, and 1:2 weight ratios of resinate to MX/HP $\beta C D$ complexes was $75 \%, 80 \%$, and $100 \%$, respectively. These results revealed that MX release increased when the portion of MX/HP $\beta C D$ complexes increased (Fig. 6), due to the combination of

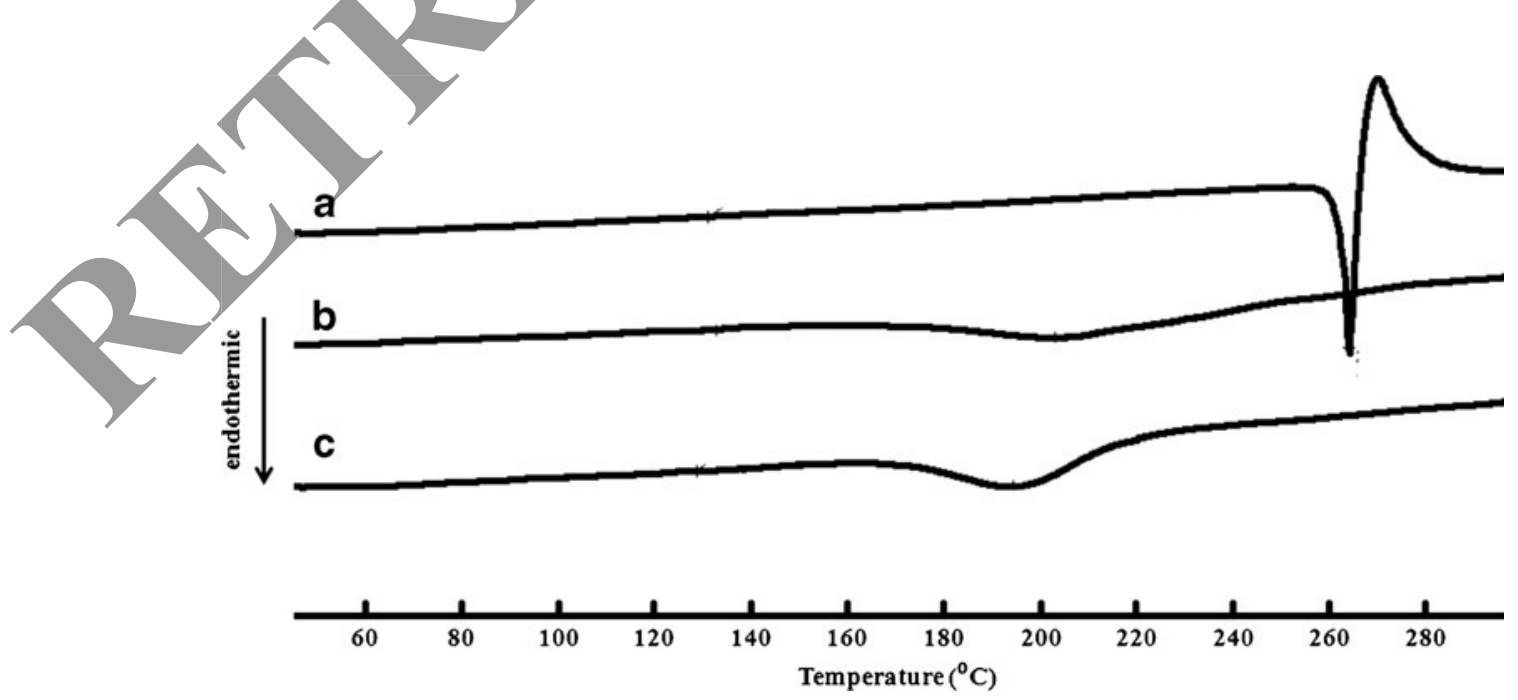

Fig. 4. DSC thermogram of $(a) \mathrm{MX},(b)$ Dowex ${ }^{\circledR}$ resin, and $(c)$ MX resinate 

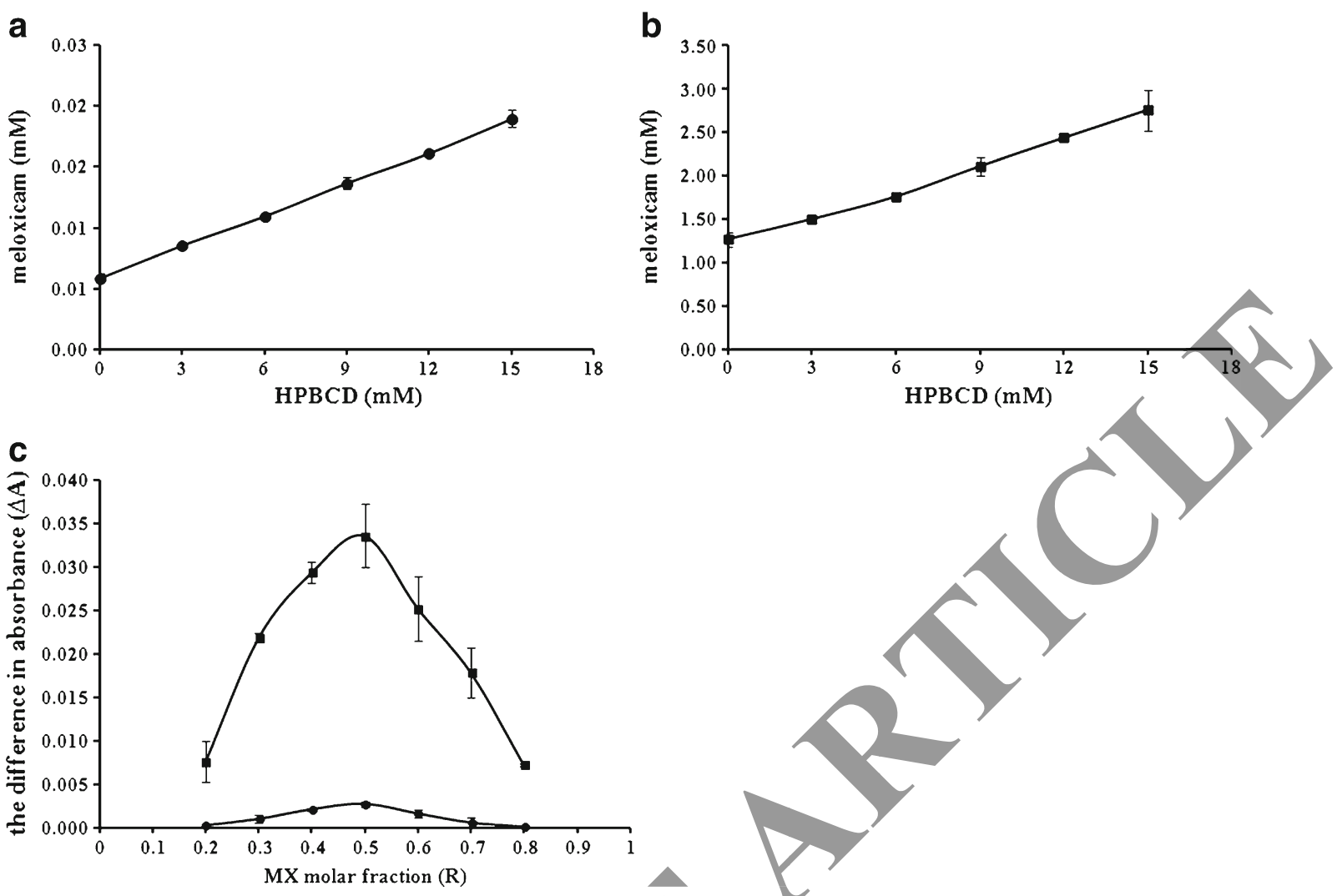

Fig. 5. Phase solubility diagrams of the $\mathrm{MX}$ in the presence of $\mathrm{HP} \beta \mathrm{CD}$ at (a) $\mathrm{pH} 1.2$ and (b) $\mathrm{pH} 6.8$, and (c) continuous variation plots for MX and $\mathrm{HP} \beta \mathrm{CD}$ systems from absorbance measurements at (filled circle) $\mathrm{pH} 1.2$ and (filled square) $\mathrm{pH} 6.8$

increasing of $\mathrm{MX}$ release by $\mathrm{MX} / \mathrm{HP} \beta \mathrm{CD}$ complexes via in situ complexation and MX release from the resinate (26). Complete MX release within $6 \mathrm{~h}$ was obtained for the mixture with a 1:2 weight ratio of resinate and MX/HP $\beta C D$ complexes. Therefore, the mixture with a 1:2 weight ratio of resinate and $\mathrm{MX} / \mathrm{HP} \beta \mathrm{CD}$ complexes was used to formulate the oral disintegrating tablet in the next experiments.

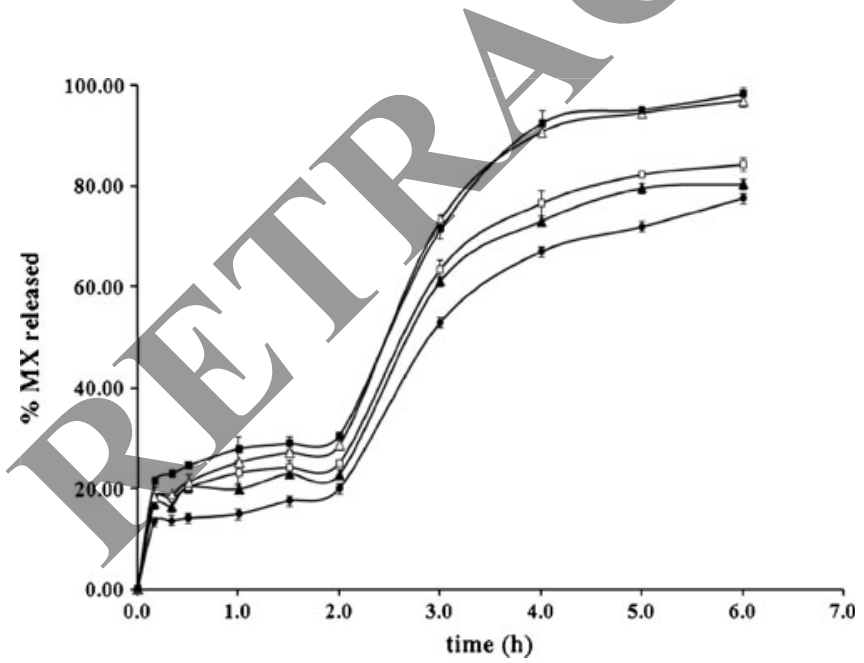

Fig. 6. Dissolution profiles of $M X$ resinate, $M X / H P \beta C D$ complexes, and the resinate and the MX/HP $\beta \mathrm{CD}$ complexes mixture powders at various ratios; (filled circle) MX resinate, (filled square) MX/HP $\beta C D$ complexes, (filled upright triangle) the mixture at 1:0.5, (open square) 1:1 and (open upright triangle) 1:2 weight ratios of resinate to MX/ $\mathrm{HP} \beta \mathrm{CD}$ complexes

\section{Preparation of Meloxicam ODTs}

ODTs containing an equivalent dose of $\mathrm{MX}(7.5 \mathrm{mg})$ in various forms (free drug (F1), resinate (F2), MX/HP $\beta C D$ complexes (F3), and the mixture with a 1:2 weight ratio of resinate and $\mathrm{MX} / \mathrm{HP} \beta \mathrm{CD}$ complexes (F4)) were formulated and evaluated. The results showed that the MX form affected the disintegration time and hardness of the tablets (Fig. 7). The disintegration times were longer and the tablets were harder for tablets formulated with $\mathrm{MX} / \mathrm{HP} \beta \mathrm{CD}$ complexes

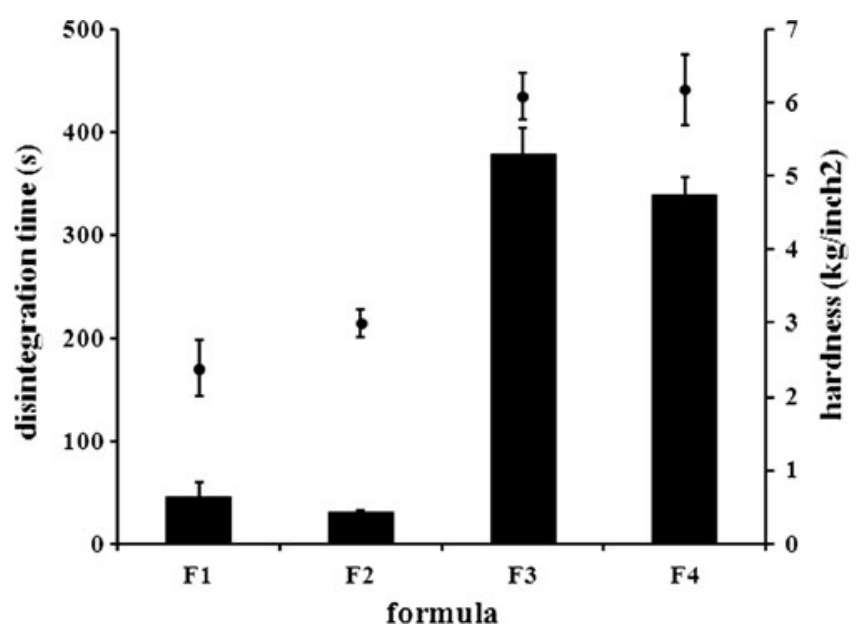

Fig. 7. Disintegration times (bar graph) and hardness (dot graph) of meloxicam ODTs 

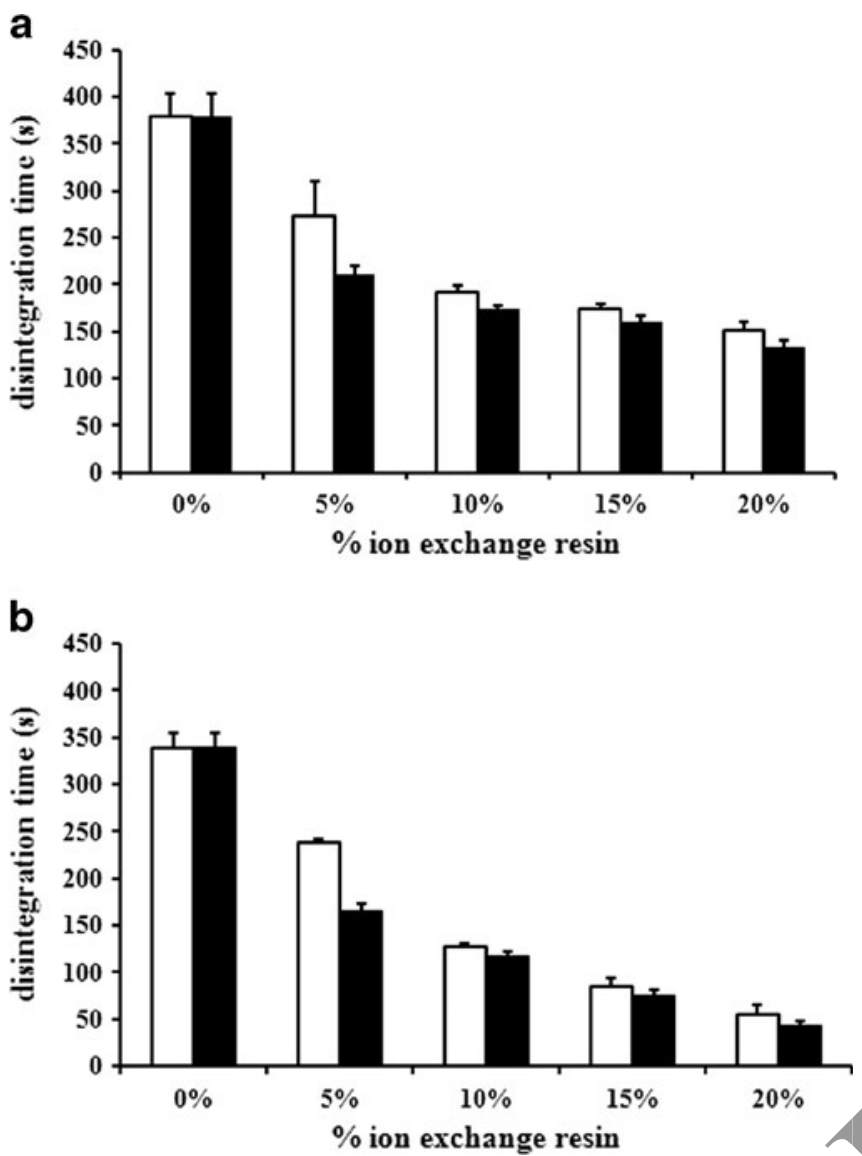

Fig. 8. Disintegration times of MX ODTs (a) F3 and (b) F4 with different amounts of ion exchange resins (white bar) Dowex ${ }^{\circledR} 1 \times 2-200$ and (black bar) Amberlite® IRP-69 improve the tablet disintegration times, ion exchange resin (Amberlite ${ }^{\circledR}$ IRP-69 and Dowex ${ }^{\circledR} 1 \times 2-200$ ) were selected as additional disintegrants. Figure 8 shows disintegration times of tablets containing various amounts of ion exchange resins $(5 \%, 10 \%, 15 \%$, and $20 \%)$. Disintegration times of tablet decreased with increasing amounts of ion exchange resin (up to $20 \%$ ). Rapid disintegration times were observed for both Amberlite ${ }^{\circledR}$ IRP-69 and Dowex ${ }^{\circledR}$ 1x2-200 (Fig. 8) due to increases in water uptake and swelling with ion exchange resin concentration (30). However, increasing the ion exchange resin concentration above $20 \%$, not only decreased the disintegration time (data not shown) but also caused an unacceptable gritty sensation in the mouth and poor hardness that caused tablet erosion during handling and storage. Therefore, $20 \%$ was the optimal level of ion exchange resin for meloxicam ODTs. Figure 8 also shows the influence of ion exchange resin type on disintegrátion time. Tablet disintegra-

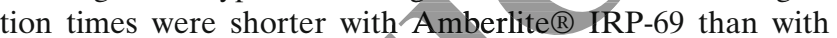
Dowex ${ }^{\circledR} 1 \times 2-200$, which might be related to the chemical structure and properties of these resins $(21,31)$. Both resins have excellent water uptake and swelling (volume and weight) properties that related to their effects on tablet disintegration (32). Tablets containing Amberlite ${ }^{\circledR}$ IRP-69 disintegrated faster due primarily to the faster water absorption and swelling than tablets containing Dowex ${ }^{\circledR}$ resin (33). This was consistent with previous work where Amberlite $\AA$ IRP-69 gave faster disintegration than other commercial ion exchange resin, especially Dowex® 1x2-200 (34). Thus, Amberlite® IRP-69 caused shorter disintegration time than Dowex ${ }^{\circledR} 1 \times 2-200$ (Fig. 8), and it was selected as an additional disintegrant to improve disintegration times for tablets containing $\mathrm{MX} / \mathrm{HP} \beta \mathrm{CD}$ complexes (F5) and mixtures of resinate and MX/HP $\beta C D$ complexes (F6). However, the tablets containing MX/HP $\beta C D$ complexes (Fig.8a) disintegrated more slowly than tablets containing a 1:2 weight ratio of resinate and MX/HP $\beta C D$ complexes (Fig.8b).

(F3) and the mixture with a 1:2 weight ratio of resinate and $\mathrm{MX} / \mathrm{HP} \beta \mathrm{CD}$ complexes (F4) than for tablets formulated with the free drug and the resinate (F1 and F2). The disintegration time was prolonged with increasing the hardness that was caused by the strengthening stronger attractive intermolecular forces among the particles in the tablets increase the hardness, hinder water penetration and prolong the disintegration time (27). $\mathrm{HP} \beta \mathrm{CD}$ in F3 and F4 contains waters of crystallization (14\%) that increases binding among the particles, thus producing stronger tablets (28). This also has implications for the disintegration time of the tablets, and the disintegration time increases with the HPBCD concentration (29). Disintegration times were slightly longer for F3 than F4 (Fig. 7) because this tablet contained more HP $\beta$ CD more than F4 (about 10\%).

Regardless of the formula, the tablets containing HP $\beta C D$ had unexpectedly long disintegration times (F3 and F4). To

\section{Evaluation of Meloxicam ODTs}

Tablets from F1, F2, F5, and F6 were selected and evaluated for optimal ODTs. There were no significant differences in the weight, thickness, diameter, and hardness of these tablets, Table II. For all tablets, the hardness was approximately $3 \mathrm{~kg} / \mathrm{in}^{2}$, and the friability was below the acceptable limit $(<1 \%)$, indicating that tablet hardness was high enough to withstand erosion during handling and storage. Tablets from F1, F2, and F6 disintegrated rapidly within $60 \mathrm{~s}$, the acceptable limit for ODTs. The rapid disintegration of tablets was due to the two types of super-disintegrants (Kollidon ${ }^{\circledR} C L$ and Amberlite $\AA$ IRP-69). Kollidon ${ }^{\circledR} C L$ has wicking ability that is a principal mechanism of disintegration (35), while Amberlite $₫$ IRP-69 has a combination of wicking and swelling properties for

Table II. Evaluation of Parameters of Meloxicam ODTs

\begin{tabular}{|c|c|c|c|c|c|c|c|c|c|}
\hline Formula & $\begin{array}{l}\text { Weight } \\
(\mathrm{mg}) n=20\end{array}$ & $\begin{array}{l}\text { Thickness } \\
(\mathrm{mm}) n=20\end{array}$ & $\begin{array}{l}\text { Diameter } \\
(\mathrm{mm}) n=20\end{array}$ & $\begin{array}{c}\text { Hardness } \\
\left(\mathrm{kg} / \text { in. }^{2}\right) n=20\end{array}$ & $\begin{array}{l}\text { Friability } \\
\text { (\%) }\end{array}$ & $\begin{array}{c}\text { In vitro } \\
\text { DT (s) } n=6\end{array}$ & $\begin{array}{c}\text { In vivo } \\
\text { DT (s) } n=6\end{array}$ & $\begin{array}{l}\text { Wetting time } \\
\text { (min) } n=3\end{array}$ & $\begin{array}{l}\text { MX content } \\
(\% \text { LA) } n=3\end{array}$ \\
\hline F1 & $199.16 \pm 3.27$ & $2.03 \pm 0.03$ & $9.61 \pm 0.02$ & $2.39 \pm 0.39$ & 0.99 & $46.17 \pm 13.59$ & $50.00 \pm 11.98$ & $1.03 \pm 0.11$ & $\overline{106.51 \pm 1.49}$ \\
\hline $\mathrm{F} 2$ & $202.99 \pm 5.81$ & $2.09 \pm 0.15$ & $9.64 \pm 0.05$ & $3.00 \pm 0.18$ & 0.77 & $30.17 \pm 1.94$ & $42.17 \pm 5.19$ & $0.76 \pm 0.11$ & $103.00 \pm 4.62$ \\
\hline F5 & $200.31 \pm 3.72$ & $2.06 \pm 0.07$ & $9.60 \pm 0.01$ & $2.70 \pm 0.39$ & 0.62 & $133.00 \pm 6.93$ & $89.67 \pm 15.16$ & $3.21 \pm 0.85$ & $100.62 \pm 3.24$ \\
\hline F6 & $207.43 \pm 3.75$ & $2.05 \pm 0.06$ & $9.60 \pm 0.01$ & $2.94 \pm 0.27$ & 0.80 & $44.00 \pm 3.58$ & $62.67 \pm 21.27$ & $2.29 \pm 0.14$ & $99.78 \pm 3.16$ \\
\hline
\end{tabular}



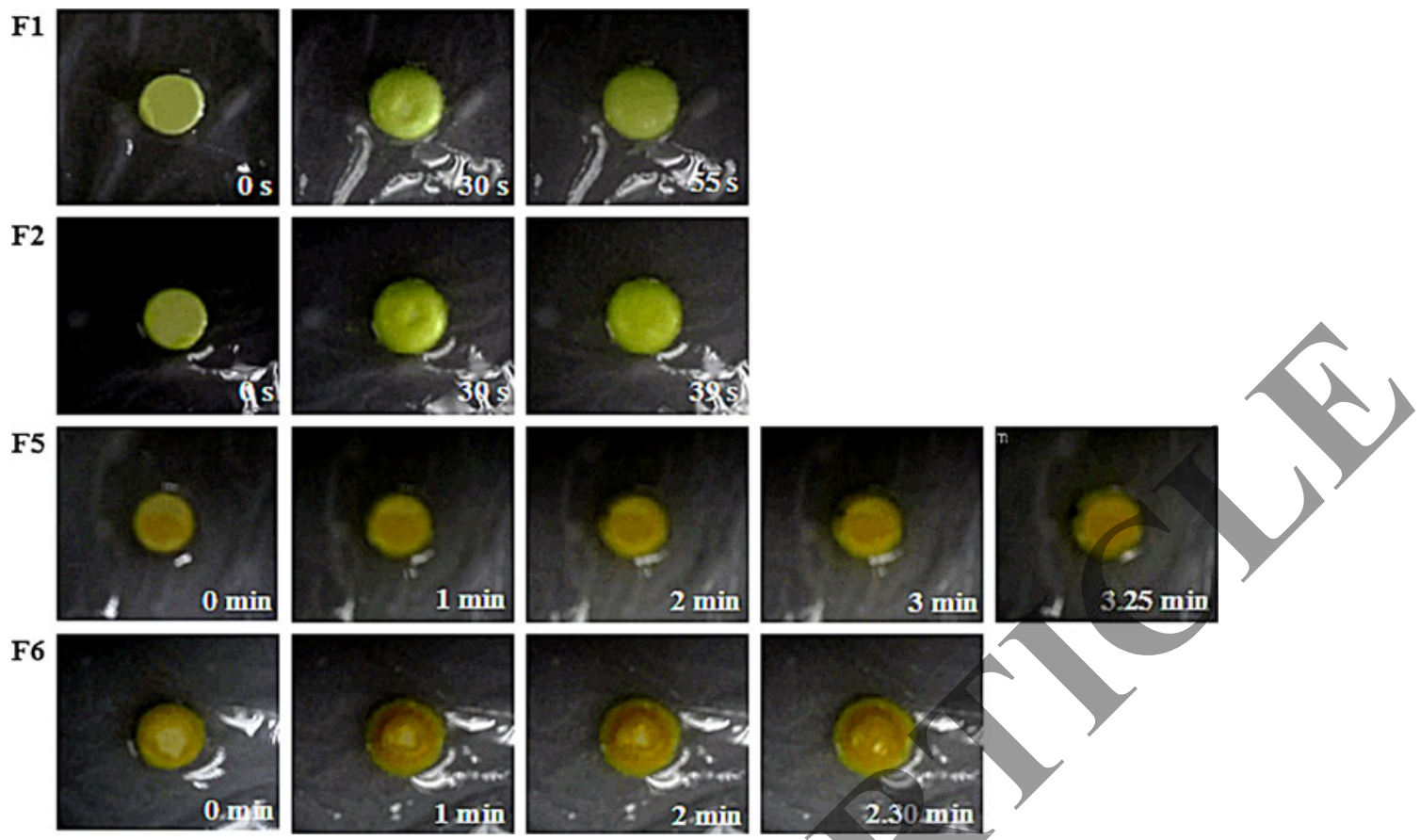

Fig. 9. Images of tablet at several times during the wetting of tablets

disintegration (32). When the tablet is exposed to water, the Kollidon ${ }^{\circledR}$ CL and Amberlite ${ }^{\circledR}$ IRP-69 pull water through capillaries and the resin swelled, and the tablet softened and disintegrated. Moreover, Comprecel ${ }^{\circledR}$ M102 D+ has properties that contribute to tablet disintegration by wicking and swelling mechanisms $(35,36)$. However, the disintegration time of F5 was longer than $60 \mathrm{~s}$ although the tablet contained ion exchange resin. This result implies that the binding properties of $\mathrm{HP} \beta C D$ that hinder water penetration dominated the effect of ion exchange resin on tablet disintegration time (27).

The in vivo disintegration time of tablets was evaluated by healthy volunteers. The in vivo tablet disintegration times were slightly longer than the in vitro times, due to the very small volume of human saliva $(<1 \mathrm{ml})$ that penetrated the tablet relative to the large volume of disintegration medium

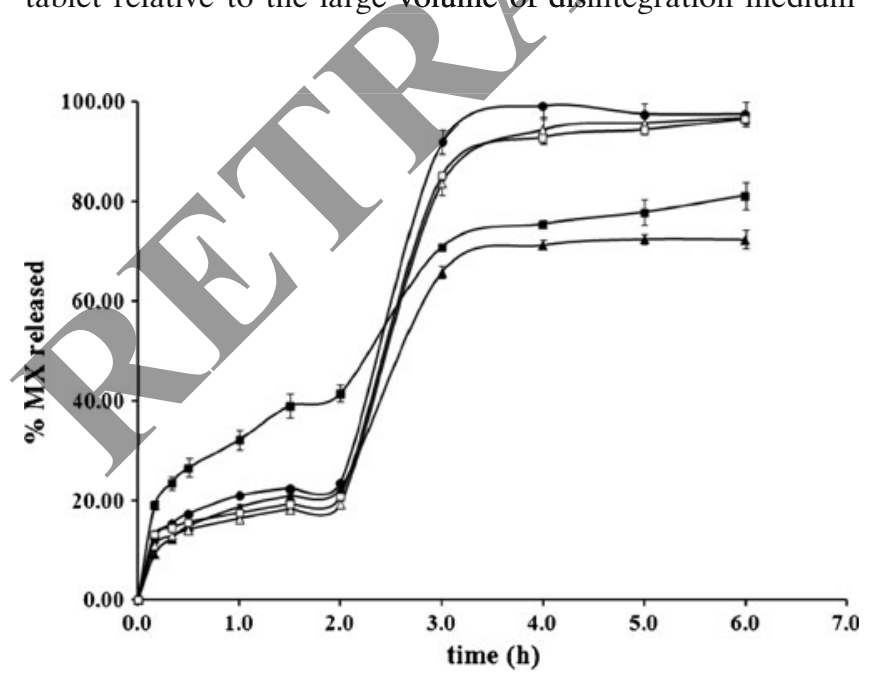

Fig. 10. Dissolution profiles of MX from tablets; (filled circle) marketed product (mobic $\left.{ }^{\circledR}\right),($ filled upright triangle) $\mathrm{F} 1$, (filled square) F2, (open upright triangle) F5, and (open square) F6
(Table II) (37). This result was consistent with previous studies where disintegrations times were shorter for larger volumes of disintegration medium and stronger agitation (38). This behavior was further evaluated by determining the wetting times of tablets by artificial saliva. The time to completely wet a tablet coincided with the in vitro and in vivo disintegration times, supporting the above explanation. F1 and F2 were completely wetted within a minute, while the wetting times were longer for F5 and F6 due to the HP $\beta$ CD in the tablets (39). Figure 9 shows the images of tablet at several times during the wetting test. The tablets absorbed a large amount of water and swelled without losing their shape, i.e., the tablets softened and their size increased. This result indicated that tablet disintegration was affected by the wicking and swelling properties of the super-disintegrants (Kollidon ${ }^{\circledR} C L$ and Amberlite ${ }^{\circ}$ IRP-69). The wicking property relates related to the porosity and may also correlate with the wetting behavior of the tablet (40). The MX content in the tablets was expressed as \% labeled amount. All formulations had MX contents within the assay limit (90\%$110 \%$ ) specified in the USP meloxicam tablet monograph (10).

Table III. Taste Evaluation of Meloxicam ODTs

\begin{tabular}{lllll}
\hline & \multicolumn{2}{l}{ Bitter level $^{\mathrm{a}}$} \\
\cline { 2 - 5 } Volunteers & F1 & F2 & F5 & F6 \\
\hline 1 & 2 & 1 & 2 & 1 \\
2 & 1 & 0 & 1 & 1 \\
3 & 2 & 1 & 2 & 0 \\
4 & 2 & 0 & 1 & 1 \\
5 & 2 & 0 & 2 & 0 \\
6 & 2 & 1 & 2 & 1 \\
\hline
\end{tabular}

${ }^{a}$ Bitterness levels: $0=$ tasteless, $1=$ slightly bitter, $2=$ moderately bitter, and $3=$ strongly bitter 


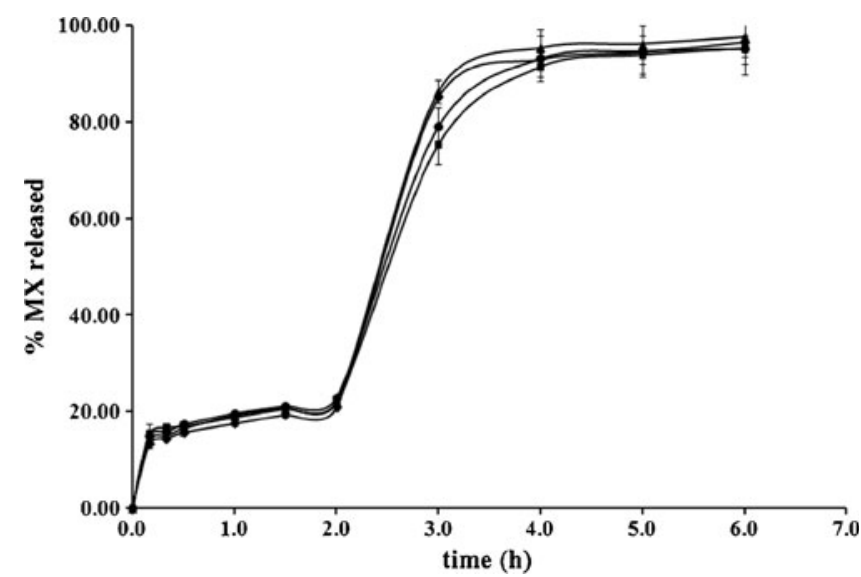

Fig. 11. Dissolution profiles of MX from the optimized formulation (F6) after (filled diamond) 0, (filled square) 1, (filled upright triangle) 3 , and (filled circle) 6 months storage

The dissolution profiles of formulated ODTs (F1, F2, F5, and F6) and the marketed product (mobic $\AA$ ) are shown in Fig. 10. In acidic medium $(0.1 \mathrm{~N} \mathrm{HCl})$, all formulae except $\mathrm{F} 2$ released less than $20 \%$ of the MX due to its poor solubility at acidic $\mathrm{pH}$ values. When the $\mathrm{pH}$ was changed to $\mathrm{pH} 6.8$, the $\mathrm{MX}$ release dramatically increased due to its greater solubility and ionization. The dissolution profile of the tablets containing the free drug (F1) released approximately $60 \%$ of the MX within $6 \mathrm{~h}$, which was less than the other formulae (F2, F5, F6). The tablets containing resinate $(\mathrm{F} 2)$ released approximately $80 \%$ of the MX within $6 \mathrm{~h}$, which was more than the free drug (F1) case. This finding can be explained by the hydrophilicity of ion exchange resin. In the dissolution medium, the tablet disintegrated by the mechanisms mentioned above, which liberated the resinate from the tablet. The ion exchange resin allowed aqueous solutions to enter the three-dimensional resin structure and rapidly hydrate the MX resinate, thereby enhancing the dissolution rate (15). The anions (i.e., $\mathrm{Cl}^{-}$and $\mathrm{PO}_{4}{ }^{3-}$ ) in the release medium displaced the loaded MX from the resinate via ion exchange reactions (Eq.6), and the liberated MX diffused through the cross-linked resin matrix and was released. Moreover, each individual MX molecule was bound to a functional site on the resin, reducing the crystal lattice energy. The state of MX in the resinate changes from crystalline to amorphous, which might enhance the rate of MX dissolution $(15,41)$. However, MX was not completely released from this tablet, which might be attributed to the equilibrium of the release process via the ion exchange reaction.

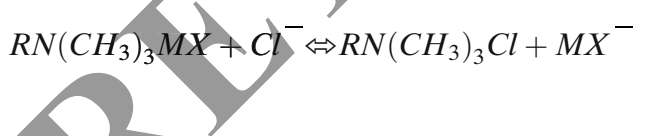

Tablets with $\mathrm{MX} / \mathrm{HP} \beta \mathrm{CD}$ complexes (F5) and the mixture with a 1:2 weight ratio of resinate and $\mathrm{MX} / \mathrm{HP} \beta \mathrm{CD}$ complexes (F6) provided complete MX release $(100 \%)$ within $6 \mathrm{~h}$. This finding indicated that $\mathrm{HP} \beta \mathrm{CD}$ enhanced MX dissolution. MX formed an in situ inclusion complex with $\mathrm{HP} \beta C D$ at a 1:1 stoichiometric ratio during tablet disintegration and $\mathrm{MX}$ dissolution, as above mentioned. The inclusion complexes were more hydrophilic and wetted more rapidly than the free drug. The dissolution profile of F5 was faster and higher than the profiles of the free drug (F1) and MX resinate (F2) formulations. These results were consistent with the previous study where cyclodextrin derivatives increased the release of aceclofenac from directly compressible tablets (42). In the case of tablets with the mixture of a 1:2 weight ratio of resinate and $\mathrm{MX} / \mathrm{HP} \beta \mathrm{CD}$ complexes $(\mathrm{F} 6)$, the $\mathrm{MX}$ release was due to the combination of MX release by the MX/ $\mathrm{HP} \beta \mathrm{CD}$ complexes and MX resinate via in situ inclusion complexation and ion exchange reactions that provided complete MX release within $6 \mathrm{~h}$. The complete MX release by F5 and F6 was similar to the release of the commercial product, but the dissolution rate for F5 and F6 was slightly slower than the commercial product due to the diffusion of the MX through the tortuous cross-linked structure of the resin and HPBCD (22).

Table III presents results from the taste evaluation of ODTs with various MX forms compared to the free drug (F1) reference. The level of bitter taste from F2 and F6 was significantly lower than F1 ( $p$ value $<0.05$ analyzed from Wilcoxon signed rank test), i.e., 0.012 and 0.019 for F2 and F6, respectively. In contrast, the bitterness level of F5 was not significantly different from $\mathrm{F} 1$. This finding confirmed that the tablets with resinate $(\mathrm{F} 2)$ and the mixture with a 1:2 weight ratio of resinate and $\mathrm{MX} / \mathrm{HP} \beta \mathrm{CD}$ complexes (F6) successfully masked the bitter taste of MX, while the MX/HP $\beta C D$ complexes in F5 did not. However, only tablets containing the 1:2 weight ratio of resinate and $\mathrm{MX} / \mathrm{HP} \beta \mathrm{CD}$ complexes (F6) successfully masked the bitter taste of MX and enhanced MX dissolution. Therefore, F6 was selected as the best formulation and was investigated for stability.

In the stability study, F6 were examined after $0,1,3$, and 6 months of storage and there were no significant changes in the appearance of the tablets and their MX content, which was $99.78 \pm 3.16 \%, 101.48 \pm 2.11 \%, 100.58 \pm 0.18 \%$, and $100.51 \pm$ $2.12 \%$ after $0,1,3$ and 6 months, respectively. The in vitro dissolution profiles of tablets stored for $0,1,3$ and 6 months are shown in Fig. 11. There was no significant difference in the release profiles of fresh and stored samples, and the F6 tablets stable at least for 6 months.

\section{CONCLUSIONS}

Taste-masked meloxicam ODTs with enhanced dissolution were successfully prepared using a combination of ion exchange resin and cyclodextrin with a 1:2 weight ratio of resinate and $\mathrm{MX} / \mathrm{HP} \beta \mathrm{CD}$ complexes. This formulation demonstrated a good level of taste, rapid disintegration, complete MX dissolution, and good stability. Thus, this tablet is advantageous for poorly water-soluble drugs with bitter taste and increases the convenience and palatability of ODTs.

\section{ACKNOWLEDGMENTS}

The authors wish to thank the Commission of Higher Education (Thailand), the Thailand Research Funds through the Golden Jubilee PhD Program (Grant No. PHD/0001/2553) and the Silpakorn University Research and Development Institute for financial support (Grant No. SURDI 55/02/2555).

\section{REFERENCES}

1. Sastry SV, Nyshadham JR, Fix JA. Recent technological advances in oral drug delivery-a review. Pharm Sci Technol Today. 2000;3(4):138-45. 
2. Hirani JJ, Rathod DA, Vadalia KR. Orally disintegrating tablets: a review. Trop J Pharm Res. 2009;8:161-72.

3. Mohapatra A, Parikh RK, Gohel MC. Formulation, development and evaluation of patient friendly dosage forms of metformin, part-I: orally disintegrating tablets. Asian J Pharm. 2008;2:167-71.

4. Bhise K, Shaikh S, Bora D. Taste Mask, design and evaluation of an oral formulation using ion exchange resin as drug carrier. AAPS PharmSciTech. 2008;9(2):557-62.

5. Anand V, Kandarapu R, Garg S. Ion-exchange resins: carrying drug delivery forward. Drug Discov Today. 2001;6:905-14.

6. Burke GM, Mendes RW, Jambhekar SS. Investigation of the application of ion exchange resins as a sustained release drug delivery system for propranolol hydrochloride. Drug Dev Ind Pharm. 1986;12:713-32.

7. Leea CW, Kima SJ, Youna YS, Widjojokusumoa E, Leea YH, Kimb J, et al. Preparation of bitter taste masked cetirizine dihydrochloride/ $\beta$-cyclodextrin inclusion complex by supercritical antisolvent (SAS) process. J Supercrit Fluid. 2010;5(1):348-57.

8. Brewster ME, Loftsson T. Cyclodextrins as pharmaceutical solubilizers. Advanced Drug Delivery Reviews. 2007;59:645-66.

9. Loftsson T, Brewster ME. Pharmaceutical applications of cyclodextrins. 1. Drug solubilization and stabilization. J Pharm Sci. 1996;85:1017-25.

10. The United State Pharmacopoeia XXXII/National FormulationXXVII. The United States Pharmacopoeial Convention. Rockville, MD; 2009.

11. Kunin R. Ion exchange resins. New York: Wiley; 1963.

12. Sriwongjanya M, Bodmeier R. Entrapment of drug-loaded ionexchange particles within polymeric microparticles. Int J Pharm. 1997;158:29-38.

13. Samprasit W, Rojanarata T, Akkaramongkolporn P, Ngawhirunpat $\mathrm{T}$, Sila-On W, Opanasopit P. Improvement of drug loading onto ion exchange resin by cyclodextrin inclusion complex. Drug Dev Ind Pharm. 2013. doi:10.3109/03639045.2012.729593.

14. Job P. Job's plot analyses for the 2-CG and 3-CG complexes were consistent with 1:1 stoichiometry. Ann Chim. 1928;9:113-34.

15. Guo X, Chang RK, Hussain MA. Ion-exchange resins as drug delivery carriers. J Pharm Sci. 2009;98(11):3886-902.

16. Gohel M, Patel M, Amin A, Agrawal R, Dave R, Bariya N. Formulation design and optimization of mouth dissolve tablets of nimesulide using vacuum drying technique. AAPS PharmSciTech. 2004;36:1-6.

17. Bi Y, Sunada H, Yonezawa Y, Danjo K, Otsuka A, Iida K. Preparation and evaluation of a compressed tablet rapidly disintegrating in the oral cavity. Chem Pharm Bull. 1996;44:2121-7.

18. Luger P, Daneck K, Trummlitz WEG, Wagner K. Structure and physicochemical properties of meloxicam, a new NSAID. Eur J Pharm Sci. 1996;4:175-87.

19. Pisal S, Zainnuddin R, Nalawade P, Mahadik K, Kadam S. Molecular properties of ciprofloxacin-Indion 234 complexes. AAPS PharmSciTech. 2004;5(4):1-8.

20. Sriwongjanya M, Bodmeier R. Entrapment of drug-loaded ionexchange particles within polymeric microparticles. Int J Pharm. 1997;158:29-38

21. Dowex product literature. http://www.dow.com. Accessed 26 Nov 2012.

22. Jeong $\mathrm{SH}_{3}$ Park $\mathrm{K}$. Drug loading and release properties of ionexchange resin complexes as a drug delivery matrix. Int J Pharm. 2008;361:26-32.

23. Higuchi T, Kristiansen $H$. Binding specificities between small organic solutes in aqueous solutions: classification of some solutes onto two groups according to binding tendencies. J Pharm Sci. 1970;59:1601-8.

24. Obaidat AA, Khanfar RA, Khawam MN. The effect of $\beta$-cyclodextrin on the solubility and dissolution rate of meloxicam and investigation of the driving force for complexation using molecular modeling. J Incl Phenom Macrocycl Chem. 2009;63:273-9.

25. Sinko PJ. Martin's physical pharmacy and pharmaceutical sciences. London: Lippincott Williams \& Wilkins; 2011. p. 197-222.

26. Jug M, Bećirević-Laćan M. Influence of hydroxypropyl- $\beta$-cyclodextrin complexation on piroxicam release from buccoadhesive tablets. Eur J Pharm Sci. 2004;21:251-60.

27. Sheshala R, Khan N, Chitneni M, Darwis Y. Formulation and in vivo evaluation of ondansetron orally disintegrating tablets using different superdisintegrants. Arch Pharm Res. 2011;34(11):1945-56.

28. Fenyresi E, Shirankura O, Szejtli J, Nagai T. Properties of cyclodextrin polymer as a tableting aid. Chem Pharm Bull. 1984;32:665-9.

29. Ghorab MM, Abdel-Salam HM, El-Sayad MA, Mekhel MM. Tablet formulation containing meloxicam and $\beta$-cyclodextrin: mechanical characterization and bioavailability evaluation. AAPS PharmSciTech. 2004;5(4):1-6.

30. Rudnic EM, Rhodes CT, Welsh S, Bernardo P. Evaluation of the mechanism of disintegrant action. Drug Dev Ind Pharm. 1982;8:87-109.

31. Amberlite product literature. http://www.rohmhaas.com. Accessed 26 Nov 2012.

32. Akkaramongkolporn P, Ngawhirunpat T, Nunthanid J, Opanasopit P. Effect of a pharmaceutical cationic exchange resin on the properties of controlled release diphenhydramine hydrochloride matrices using Methocel K4M or Ethocel $7 \mathrm{cP}$ as matrix formers. AAPS PharmSciTech. 2008;9(3):899-908.

33. Sriwongjanya M, Bodmeier R. Effect of ion exchange resins on the drug release from matrix tablets. Eur J Pharm Biopharm. 1998;46:321 7 .

34. Pattarakan N, Opanasopit P, Ngawhirunpat T, Akkaramongkolporn P. Application of ion exchange resins as tablet disintegrants. The 26th Annual Research Conference in Pharmaceutical Science. 04 December 2009. Bangkok, Thailand.

35. Kornblum SS, Stoopak SB. A new tablet disintegrating agent: cross-linked polyvinylpyrrolidone. J Pharm Sci. 1973;62(1):43-9.

36. Jivraj M, Martini LG, Thomson CM. An overview of the different excipients useful for the direct compression of tablets. Pharm Sci Tech Today. 2000;3:58-62.

37. Narazaki R, Harada T, Takami N, Kato Y, Ohwaki T. A new method for disintegration studies of rapid disintegrating tablet. Chem Pharm Bull. 2004;52(6):704-7.

38. Bi Y, Hisakadzu S. Preparation and evaluation of a compressed tablet rapidly disintegrating in the oral cavity. Chem Pharm Bull. 1996;44:2121-7.

39. Fenyresi E, Shirankura O, Szejtli J, Nagai T. Properties of cyclodextrin polymer as a tableting aid. Chem Pharm Bull. 1984;32:665-9.

40. Jinichi F, Etsuo Y, Yasuo Y, Terada K. Evaluation of rapidly disintegrating tablets containing glycine and carboxymethylcellulose. Int J Pharm. 2006;310:101-9.

41. Akkaramongkolporn P, Yononemochi E, Terada K. Molecular state of chlorpheniramine in resinates. Chem Pharm Bull. 2000;48(2):231-4.

42. Dahiya S, Pathak K. Influence of amorphous cyclodextrin derivatives on aceclofenae release from directly compressible tablets. Pharmazie. 2007;62:278-83. 